\title{
Self-reported Competency Ratings of Graduates of a Problem-based Medical Curriculum
}

\author{
Henk G. Schmidt, PhD, and Henk T. van der Molen, PhD
}

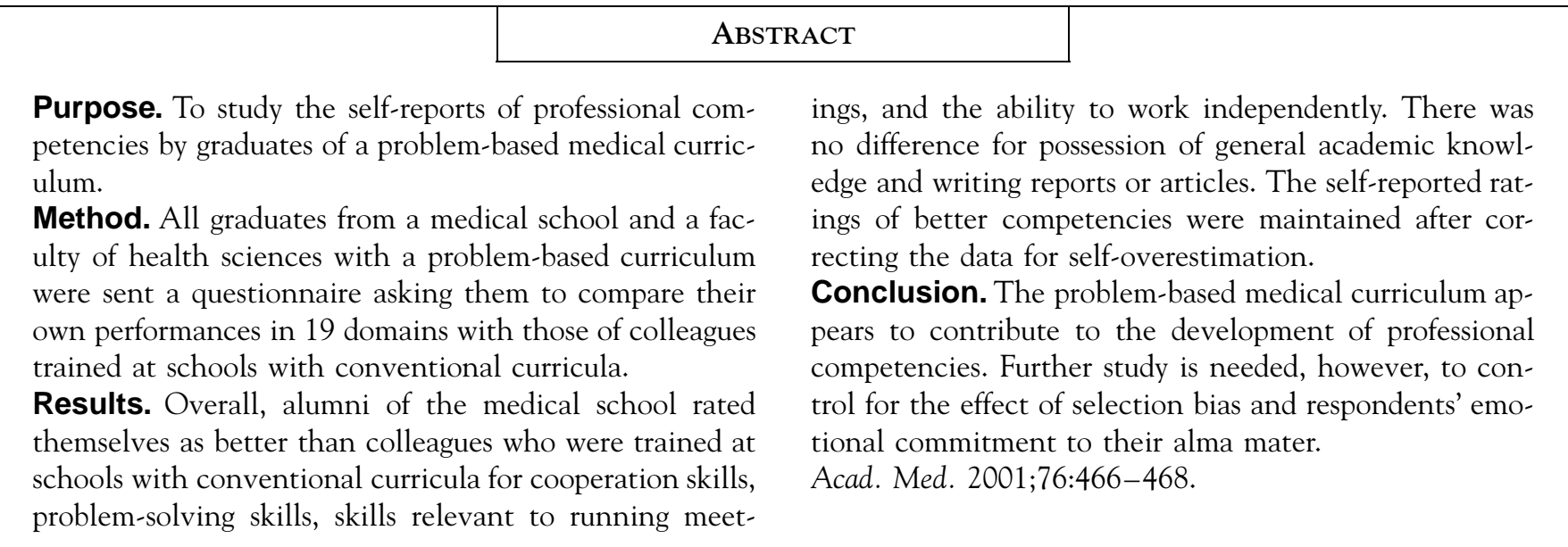

The number of studies describing longterm effects of education on graduates of medical schools is fairly limited. This is particularly the case for studies of the effects of conventional education compared with innovative curricula employing such methods as problem-based learning, although studies involving students are more common. ${ }^{1,2}$ The reasons for the limited availability of data on graduates are threefold. First, comparing graduates from different schools on a number of relevant characteristics

At the time the paper was uritten, Dr. Schmidt was professor of psychology, Maastricht University. He is now professor of psychology, Erasmus University, Rotterdam, The Netherlands. Dr. van der Molen is professor of psychology, Open University and University of Groningen, Groningen, The Netherlands.

Correspondence and requests for reprints should be addressed to Dr. Schmidt, P.O. Box 1738, 3000 DR Rotterdam, The Netherlands; e-mail:〈h.schmidt@ fsw.eur.nl>. and then ascribing differences to the impact of the particular curricula studied is tricky business because the students may have been already different to begin with. Second, collecting reliable data is very difficult and expensive because graduates tend to change positions, often leaving no trace as to their whereabouts. And third, many relevant competencies, such as teamwork skills, are difficult to measure directly and require extended observation periods.

Consequently, our scant knowledge of how well graduates from problembased medical schools are doing in professional practice can almost be summarized in one paragraph: Graduates from problem-based medical schools feel better prepared for professional practice than do their counterparts from conventional schools ${ }^{3}$; they think that they are better able to communicate with their patients ${ }^{4}$; and, while one study indicates they are better self-di- rected learners, ${ }^{5}$ other studies indicate they are not. ${ }^{6,7}$ Woodward and colleagues, at McMaster University, have demonstrated that supervisors characterize graduates from that problembased school as better communicators with patients ${ }^{8}$; another study showed that graduates from a problem-based curriculum in primary care practice spent more time on individual patients and referred them less often to specialized psychiatric services. ${ }^{9}$

The present study asked graduates from a problem-based medical school to compare their performances in professional practice with the performances of colleagues trained at schools with conventional curricula. To control for the possible effects of self-overestimation, the questionnaire included some competencies at which the graduates of the problem-based school were known to be no better than were graduates of conventional schools. 


\section{METHOD}

In the spring of 1999, all alumni of Maastricht University School of Medicine were sent a questionnaire inquiring about their current perspective on the quality of their training. They were asked to rate themselves on 19 professionally relevant skills (see Table 1). Their task was to compare themselves with colleagues who had been trained elsewhere, and to indicate on a fivepoint scale whether they consider themselves less competent, equally competent, or more competent than these colleagues ( 3 = equally competent).

Participants were 820 graduates of the medical school of Maastricht University, 418 women and 402 men, who responded to the survey. These graduates represented $39 \%$ of the total population of physicians who had graduated from this school since its inception and who had entered practice up to 19 years previously. As a comparison group, responses from 1,448 graduates $(1,109$ women and 339 men) from the health sciences faculty of the same university were included. Both curricula employ problem-based learning as their instructional approach, emphasizing problem solving, small-group work, and self-directed learning. The health sciences data are reported in the results merely to put the medical school's data into perspective.

\section{RESUlTS}

The responses by competency of medical school graduates (and faculty of health sciences graduates, for comparison only) are shown in Table 1. Medical school alumni rated themselves as better in the competencies of cooperation, problem solving, interpersonal skills, skills relevant to running meetings, and the ability to work independently. They did not rate themselves as better in the possession of general academic knowledge and writing reports or articles.

Table 1

Self-reports of Competency in 19 Skills by Graduates of a Problem-based Curriculum, University of Maastricht School of Medicine*

\begin{tabular}{|c|c|c|c|}
\hline \multirow[b]{2}{*}{ Competency } & \multicolumn{3}{|c|}{ Responses } \\
\hline & $\begin{array}{l}\text { School of } \\
\text { Medicine }\end{array}$ & $\begin{array}{c}\text { Faculty of } \\
\text { Health Sciences } \dagger\end{array}$ & Mean† \\
\hline Problem-solving skills & 3.8 & 3.7 & 3.7 \\
\hline Cooperation skills & 3.9 & 3.8 & 3.8 \\
\hline Possession of profession-relevant knowledge & 3.2 & 3.1 & 3.1 \\
\hline Possession of general academic knowledge & 3.0 & 3.3 & 3.2 \\
\hline Interpersonal skills & 4.2 & 3.9 & 4.0 \\
\hline \multicolumn{4}{|l|}{ Skills relevant to running meetings (e.g., chairing } \\
\hline a meeting) & 3.8 & 3.8 & 3.8 \\
\hline Writing reports or articles & 3.0 & 3.5 & 3.3 \\
\hline Paper presentation skills & 3.3 & 3.4 & 3.4 \\
\hline Research skills & 3.3 & 3.3 & 3.3 \\
\hline Self-directed learning skills & 3.6 & 3.5 & 3.6 \\
\hline Use of information resources & 3.7 & 3.6 & 3.6 \\
\hline Professional skills (such as physical examination) & 3.6 & 3.0 & 3.3 \\
\hline \multicolumn{4}{|l|}{ Producing new ideas to do one's work in a better } \\
\hline way & 3.6 & 3.6 & 3.6 \\
\hline Helping colleagues & 3.7 & 3.7 & 3.7 \\
\hline Productivity & 3.5 & 3.5 & 3.5 \\
\hline Ability to work independently & 3.8 & 3.9 & 3.9 \\
\hline Planning skills & 3.6 & 3.7 & 3.7 \\
\hline Efficiency, time management & 3.4 & 3.5 & 3.4 \\
\hline Ability to work under pressure & 3.4 & 3.5 & 3.4 \\
\hline
\end{tabular}

${ }^{*}$ In 1999, all graduates were asked to rate their competencies in comparison with the competencies of their colleagues from non-PBL schools using a five-point Likert-type scale ( 1 = less competent, 3 = equally competent, 5 = more competent).

†Reported only for comparison. No statistical test is reported.

To control for the possibility that the medical school graduates may have overestimated their own competencies or underestimated those of others, we established a baseline by using the scores of competencies for which there is no reason to assume that graduates from Maastricht University School of Medicine perform better than graduates from elsewhere. For instance, previous research showed that Maastricht's medical students have no more medical knowledge than do students from conventional schools. ${ }^{10}$ Nor is there reason to believe that their general academic knowledge, report writing, presentation, and research skills are more advanced, because the Maastricht curriculum pays no more attention to these topics than do other medical schools in The Netherlands. We deduced that the average self-reported competency scores on these items would be around 3.0 if these ratings were based on actual observations of one's own behavior compared with that of colleagues trained elsewhere. Because the average score on these items was 3.26, we considered a fair estimate of the amount of self-overestimation to be 0.26 . To be conservative, we established a baseline score of 3.3 to represent the value at which no difference in competence was observed.

Taking this correction into account, our findings suggest that the graduates' self-assessments of greater competency 
in cooperation, problem solving, and independent work reflect real differences rather than simple self-overestimation effects. This may be particularly true for their self-reports of competency in interpersonal skills, which align with findings from other studies in this area. ${ }^{3,4,8}$

\section{Discussion}

The findings in our study may be good news for those who believe that problem-based learning provides more than simply a pleasant learning environment, and that it contributes in significant ways to the development of professional competencies relevant to modern practice.

Despite our attempt to control for systematic distortions of the graduates' observations, however, there are at least three alternative hypotheses that may account for the data. The first is selection bias. The response rate to the survey was around $40 \%$. Although this response is acceptable for a study involving participants some of whom had left their alma mater as long as 20 years ago, it is likely that those who responded were generally more successful, which may have skewed the findings. Studies involving comparisons between volunteers and non-volunteers generally show these kinds of differences, but they tend to be small. It is, therefore, unlikely that this bias alone accounts for the findings.

A second possibility is that the graduates' responses to the items were indirect expressions of gratitude to the university: "You have been good to me. Thank you!" If this were the case, it would be a serious threat to the validity of our findings, because it would imply that the data do not reflect actual observations but instead mirror a general positive mood towards training. However, the data do not show an overall positive trend that would suggest the mood hypothesis to be likely. For example, the graduates indicated that their report-writing skills and their general academic knowledge were not better than those of colleagues trained elsewhere. To evaluate the significance of these two threats to the validity of our findings, we are preparing a follow-up study in which graduates from a university characterized largely by conventional teaching methods are asked to respond to the same items.

A third possibility is that the problem-based curriculum involved may have been so successful in transmitting the theory and purported effects of problem-based learning that graduates - even after 20 years of professional experience-cannot see themselves as anything but extremely adept problem solvers, armed with great independent working skills. This extremely unlikely possibility has no apparent methodologic cure. It would mean that, out in the health professions, graduates operate with self-images so unfalteringly positive that reality does not affect them.

\section{REFERENCES}

1. Albanese MA, Mitchell S. Problem-based learning: a review of literature on its out- comes and implementation issues. Acad Med. 1993;68:52-81.

2. Schmidt HG, Dauphinée WD, Patel VL. Comparing the effects of problem-based and conventional curricula in an international sample. J Med Educ. 1987;62:305-15.

3. Mennin SP, Kalishman S, Friedman M, Pathak D, Snyder J. A survey of graduates in practice from the University of New Mexico's conventional and community-oriented, problem-based tracks. Acad Med. 1996;71:1079_ 89.

4. Santos Gomez L, Kalishman S, Rezler AG, Skipper B, et al. Residency performance of graduates from a problem-based and a conventional curriculum. Med Educ. 1990;24: 366-75.

5. Shin JH, Haynes RB, Johnston ME. Effects of problem-based, self-directed undergraduate education on life-long learning. Can Med Assoc J. 1993;148:969-76.

6. Tolnai S. Continuing medical education and career choice among graduates of problembased and traditional curricula. Med Educ. 1991;25:414-20.

7. Tolnai S. Lifelong learning habits of physicians trained at an innovative medical school and a more traditional one. Acad Med. 1991; 66:425-6.

8. Woodward CA, McAuley RG. Can the academic background of medical graduates be detected during internship? Can Med Assoc J. 1983;129:567-9.

9. Woodward CA, Ferrier BM, Cohen M, Goldsmith A. A comparison of the practice patterns of general practitioners and family physicians graduating from McMaster and other Ontario medical schools. Teach Learn Med. 1990;2:79-88.

10. Verwijnen GM, Van der Vleuten C, Imbos T. A comparison of an innovative medical school with traditional schools: an analysis in the cognitive domain. In: Nooman Z, Schmidt HG, Ezzat E (eds). Innovation in Medical Education, An Evaluation of Its Present Status. New York: Springer Publishing, 1990. 